\title{
Pattern of Ophthalmic Consult from the Ear, Nose and Throat Ward of a Tertiary Hospital
}

\author{
OO Komolafe ${ }^{1}$ MB.Ch B, FW ACS, AA Adeosun ${ }^{2}$ MBBS, FW ACS, AM Baiyeroju ${ }^{3}$ MBBS, FW ACS \\ ${ }^{1}$ Department of Ophthalmology, Federal Medical Centre, Owo, Nigeria \\ ${ }^{2}$ Departments of Otorhinolaryngology and ${ }^{3}$ Ophthalmology, University College Hospital, Ibadan, Nigeria
}

\section{SUMMARY}

Objective: To study the pattern and indications for ophthalmic referral of patients with otorhinolaryngology problems.

Method: A retrospective study of patients who were admitted into the Ear, Nose and Throat (ENT) ward of the University College Hospital, Ibadan and had ophthalmic referral between July 2000 and June 2004. The parameters evaluated were the demography of the patient, indication for ophthalmic consult, and the contribution of the ophthalmologist towards the management of the patient.

Results: Reports on 26 patients on whom ophthalmic consults were sent were available for review. This accounted for $3 \%$ of the patients admitted during the period under review. Fourteen $(53.8 \%)$ of the consults were sent on account of proptosis and 7 (26.9\%) for complaints of poor vision. In 12 $(46.2 \%)$ of these patients, the otorhinolaryngological diagnosis was sinonasal tumour. The ophthalmologist made positive contributions to the management of 20 (76.9\%) of the patients. These included the use of lubricants/protective shield (6 [23.1\%]), tarsorrhaphy (3 [ 11.5\%]), antiglaucoma medication (2[7.7\%]) and cataract extraction (2[7.7\%]).

Conclusion: Proptosis ranked highest for ophthalmic consult from the ENT ward in this review. Close collaboration between subspecialties should be encouraged when managing visually-threatening conditions. There is also the need for a standard referral protocol.

Key words: ENT pathology, ophthalmic consult, proptosis, response time

\section{INTRODUCTION}

Ophthalmic symptoms and signs are one of the ways by which diseases of the ear, nose and throat manifest. This is because anatomically, the orbit is an important crossroad between the central nervous system and the paranasal sinuses. Such symptoms could include proptosis, epiphora and visual loss from the compression of the optic nerve and exposure keratopathy.

Some studies ${ }^{1-3}$ have evaluated the pattern of referrals to ophthalmic departments. None of these studies, however, have focussed on consults mainly from an otorhinolaryngology ward.

Effective management of visually- threatening sinonasal conditions would require collaboration between the otorhinolaryngologist and the ophthalmologist. It has been shown that ophthalmological consultation does make a significant difference in the management of patients with ocular problems from other medical and surgical units. ${ }^{3}$

At the University College Hospital, Ibadan, the Eye, Ear, Nose and Throat Department was a single department accommodated within the same ward until 1979 when it was split into two departments namely ophthalmology and otorhinolaryngology (ENT) departments. The ENT ward, a 32-bed ward was named Frank D. Martinson Ward, after a foremost otorhinolaryngologist and the first head of the department.

There had been no formal auditing of the referral pattern of patients between these two departments since they were separated. Likewise, there is a dearth of information in the literature on the pattern of ophthalmic referrals from the otorhinolaryngological division of various hospitals.

This review is aimed at evaluating indications for such referrals and the contributions of the ophthalmologists toward the management of the patients.

\section{METHODS}

The clinical record of the patients admitted into the 32-bed ENT ward of the University College Hospital, Ibadan, between July 2000 and June 2004 was reviewed.

Parameters evaluated included the patients' demographic data (age, sex), presentation of complaints, examination findings, admission diagnoses and the

${ }^{*}$ Correspondence: Dr OO Komolafe, Department of Ophthalmology, Federal Medical Centre, Owo, Nigeria • Email: kopeyemi@yahoo.co.uk 
indications for ophthalmic consult as shown in the file copy of the consult form sent. Also analysed were the recommendations made by the ophthalmologist, as well as his/her response time. The ophthalmologist's response time was defined for the purpose of this audit as the interval between when such consult was received by the ophthalmologist and when the patient had ophthalmic evaluation. This is approximated to the nearest 24 hours.

Excluded from the review were patients who had their initial referral to the otorhinolaryngologist from the ophthalmologist and patients who were managed by the two subspecialties in the accident and emergency unit of the hospital before admission into the ward. Patients with incomplete records such as missing referral forms and ophthalmologist reports were also excluded.

\section{RESULTS}

Eight hundred and sixty-six patients were admitted over the period under review. There were $534(61.7 \%)$ male patients, with a male to female ratio of 1.6:1. However, only $26(3 \%)$ patients met the criteria for inclusion in the review. The age of the patients reviewed ranged between 9 and 80 years with a mean of 40.4 years (SD 19.3). Table 1 shows the demographic data of the patients reviewed.

Table 1. Demographic characteristic of reviewed patients

\begin{tabular}{lcc}
\hline Sex Distribution & $\mathrm{N}(26)$ & $\%$ \\
\hline Male & 15 & 57.7 \\
Female & 11 & 42.3 \\
\hline Age Distribution & & \\
\hline $0-19$ & 3 & 11.5 \\
$20-39$ & 12 & 46.2 \\
$40-59$ & 6 & 23.1 \\
$60+$ & 5 & 19.2 \\
\hline
\end{tabular}

The specific indications for sending ophthalmic consults

included proptosis in $14(53.8 \%)$ patients, poor vision in 7 $(26.9 \%)$ patients, diplopia and epiphora in $2(7.7 \%)$ patients each, and ophthalmoplegia in $1(3.8 \%)$ patient. Table 2 reveals the indications for the ophthalmic consults.

The clinical diagnosis of the patients on whom such ophthalmic consults were sent included sinonasal tumour in $12(46.2 \%)$ patients, acute chronic rhinosinusitis with orbital complications in 5 ( $19.2 \%)$ patients, frontoethmoidal mucocele and nasopharyngeal tumour each in $4(15.4 \%)$ patients and fibrous dysplasia in $1(3.8 \%)$ patient. The ophthalmologist contributed positively to the patient care in $20(76.9 \%)$ of the consults sent. Table 2 also shows the recommendations of the ophthalmologists.

Table 2. Findings by the ophthalmologist and additional recommendations

\begin{tabular}{|c|c|c|c|}
\hline $\begin{array}{l}\text { Indication } \\
\text { for referral }\end{array}$ & $\begin{array}{l}\text { Additional } \\
\text { findings by } \\
\text { ophthalmologist }\end{array}$ & $\begin{array}{c}\text { No of } \\
\text { patients } \\
(\%)\end{array}$ & $\begin{array}{l}\text { Ophthalmologist } \\
\text { contributions }\end{array}$ \\
\hline Proptosis & None & $6(23.1)$ & $\begin{array}{l}\text { Lubricant/ } \\
\text { Protective shield }\end{array}$ \\
\hline Proptosis & $\begin{array}{l}\text { Exposure } \\
\text { keratopathy }\end{array}$ & $3(11.5)$ & Tarsorrhaphy \\
\hline Proptosis & Optic atrophy & $3(11.5)$ & Nil \\
\hline Proptosis & Panophthalmitis & $2(7.7)$ & Evisceration \\
\hline Poor vision & Glaucoma & $2(7.7)$ & $\begin{array}{l}\text { Antiglaucoma } \\
\text { medication }\end{array}$ \\
\hline Poor vision & Refractive error & $2(7.7)$ & $\begin{array}{l}\text { Refraction/ } \\
\text { Spectacle }\end{array}$ \\
\hline Epiphora & Lagophthalmos & $2(7.7)$ & $\begin{array}{l}\text { Lidtaping/ } \\
\text { Lubricants }\end{array}$ \\
\hline Poor vision & Cataract & $2(7.7)$ & $\begin{array}{l}\text { Cataract } \\
\text { extraction }\end{array}$ \\
\hline Poor vision & $\begin{array}{l}\text { Cornea opacity } \\
\text { from childhood } \\
\text { keratitis }\end{array}$ & $1(3.8)$ & Nil \\
\hline Diplopia & $\begin{array}{l}\text { Squint } 2^{0} \text { to } \\
\text { proptosis }\end{array}$ & $1(3.8)$ & Occlusion \\
\hline Diplopia & None & $1(3.8)$ & Nil \\
\hline $\begin{array}{l}\text { Ophthalmo- } \\
\text { plegia }\end{array}$ & None & $1(3.8)$ & Nil \\
\hline
\end{tabular}

The ophthalmologist responded within 48 hours of the consults being sent in $20(76.9 \%)$ of the cases. Four $(15.4 \%)$ of the cases were only seen 7 days after such consults had been sent, while the remaining $2(7.7 \%)$ cases were seen between 2 to 4 days after the consults had been sent.

\section{DISCUSSION}

Collaboration between sub-specialists in patient care is one way of ensuring quality care delivery hence the need for referrals and consults. Diseases of the sinonasal tract and the orbit are inseparable because of their anatomic proximity. Some $60-80 \%$ of the orbital wall constitutes the wall of the paranasal sinuses. ${ }^{4}$

Proptosis ranked highest among the indications for sending consults to the ophthalmologist. This might not be surprising. Quite a number of otorhinolaryngological pathologies possess the tendency of encroaching on the 
orbital space and as such cause forward protrusion of the globe. Adeyemo et al. ${ }^{5}$, in a review of ocular complications of sinonasal tumours among patients seen in the University College Hospital, Ibadan, showed that $70 \%$ had complications referred to the orbit. Proptosis constituted $44 \%$ of the complications. Among patients aged 19 years and below who were reviewed on account of the proptosis, the clinical diagnosis was orbital complication of rhinosinusitis. Such complications included orbital cellulitis in two cases and subperiosteal abscess in one case. This shows the changing pattern in the causes of proptosis with age. Orbital bacterial infection has been reported to be the leading cause of unilateral proptosis in children, and $60-80 \%$ of such infections are secondary to paranasal sinusitis. ${ }^{6,7}$ Ognibene et al. reported $83 \%$ of orbital complications in a 10 -year retrospective review of cases. ${ }^{8}$ Also in a review of 59 patients with complicated pan-sinusitis, Tshifularo et al. ${ }^{9}$ found that $36(61 \%)$ had complications that needed to be managed in consultation with the neurosurgeons and the ophthalmologist.

About $15.4 \%$ of the cases of proptosis for which consults were sent was due to frontoethmoidal mucocele. Frontoethmoidal mucocele, which is mucous containing cysts, caused by obstruction of the sinus orifices, has been strongly associated with ophthalmic symptoms. ${ }^{10}$ Tseng et al. found proptosis among $46.3 \%$ of the cases reviewed. ${ }^{10}$ This is less than the $75 \%$ reported by Ajaiyeoba et al. ${ }^{11}$

Seven patients had consults sent on them primarily on account of poor vision. Of interest to these consults was the fact that they were cases in which the cause of the poor vision could not be ascertained by the ENT surgeon or cases in which the poor vision could not be linked directly with the primary ENT pathology. Even though all the patients with proptosis on whom consults were sent apparently had some degree of visual impairment, the consult sent indicated the most obvious - 'the proptosis' rather than the visual impairment. The causes of poor vision found by the evaluating ophthalmologist included cataract and glaucoma in 2 patients each. Although these blinding ocular conditions may not have direct correlation with the sinonasal problems for which the patients were admitted, subjects with allergic rhinosinusitis on prolonged or high dose steroid may develop secondary cataract or glaucoma as a complication of their medication. However, this was not evaluated in the review as it was a retrospective study.

The response time by the ophthalmologists may be considered adequate as over $75 \%$ of the consults were seen within 48 hours of receiving them. However, there is little information in the literature in this respect for comparative purpose but it is the opinion of these authors that the response time could be faster. This is with the full knowledge of the irreversible visual impairment that could result from any unnecessary delay. Marshall et al. ${ }^{12}$ in their recommendation on eye care for critically ill patients suggested timely referral for patients at risk of iatrogenic ophthalmologic complications and suggested that patients who cannot maintain passive eyelid closure should receive eye care every 2 hours.

There is enough justification for most of the consults sent as the ophthalmologist was able to make useful recommendations in $76.9 \%$ of the consults reviewed. Visual outcome for patients can only be satisfactory if complications such as exposure keratopathy are prevented early in the disease process. Apart from tarsorrhaphy which was recommended for 3 patients who were already having features of exposure keratopathy, all the other eyes at risk of exposure keratopathy were commenced on generous topical ointment/lubricants and protective catellar shield. The need for such preventive measures cannot be overemphasized in developing countries where assess to corneal transplant is either not available and, where available, may not be affordable. Even though the visual outlook could not be improved in the patients with optic atrophy, the documentation of the fundoscopy findings could be of medicolegal importance as could be used for prognostic purposes.

This audit had its limitations. There was limited information in the literature, thus comparative analysis could not be done and there was no defined standard response time. There is need, therefore, for similar studies in other centres and among other subspecialties. There was also the problem of retrieval of records, a limitation common to retrospective reviews. Only 26 out of the 51 patients on whom there was some indication of ophthalmic review could be included in the audit because of incomplete or missing data. Also, the overall impact of the ophthalmologist's recommendation on improving the outcome in terms of vision for patients with proptosis who had tarsorrhapy and lubricants could not be evaluated because of loss to follow up.

Finally, findings on patients with otorhinolaryngological pathologies who were managed in collaboration with ophthalmologists has further strengthened the idea of the need for close collaboration between these subspecialties, with a view to improving the outcome among patients with visually-threatening sinonasal problems. The adoption of a standard referral protocol should also be encouraged.

\section{REFERENCES}

1. Owoeye JFA, Fafowora OF. How relevant is current Nigerian postgraduate ophthalmic training to needed practice skill? Nig J Ophthalmol 2006; 14: 5 - 8 . 
2. Carter K, Miller KM. Ophthalmology inpatient consultation. Ophthalmology 2001; 108: 1505 - 1511.0

3. Bala C, Poon AC, Joblin P, McCluskey PJ. Ophthalmologists in teaching hospitals: Do we make a difference to patient outcome. Clin Experiment Ophthalmol 2001; 29: 59 - 63.

4. El Sayed Y. Orbital involvement in sinonasal disease. Saudi J Ophthalmol 1995; 9: 29 - 37.

5. Adeyemo A, Bekibele CO, Onakoya PA. Eye complications related to sinonasal tumours in Ibadan. Nig J Ophthalmol 2003; 11: $90-93$.

6. Osguthorpe JD, Hochman M. Inflammatory sinus disease affecting the orbit. Otolarngol Clin North Am. 1993; 26: 657 671.

7. Grove AS. Orbital diagnosis. Head Neck Surg 1979: 2: 12 - 24 .

8. Ognibene RZ, Voegels RL, Bensodon RL, Butugan O. Complications of sinusitis. Am J Rhino 2004; 8:175-179.
9. Tshifularo M, Monama GM. Complications of inflammatory sinusitis in children: Institutional review. S Afr Fam Pract 2006; 48: 16 - 16c.

10. Tseng CC, Ho CY, Kao SC. Ophthalmic manifestation of paranasal sinus mucocoele. J Chin Med Assoc 2005; 68: 260 264.

11. Ajaiyeoba A, Kokong D, Onakoya A. Clinicopathologic, ophthalmic, visual profiles and management of mucocoeles in Blacks. J Natl Med Assoc 2006; 98: 63 - 66.

12. Marshall AP, Elliot R, Rolls K, Schacht S, Boyle M. Eye care in the critically ill. Clinical practice guideline. Aust Crit Care 2008; 29. Epub ahead of print. 